\title{
High-Temperature Raman Spectroscopy of Solid Oxide Fuel Cell Materials and Processes
}

\author{
Michael B. Pomfret ${ }^{a}$, Jeffrey C. Owrutsky ${ }^{b}$, Robert A. Walker ${ }^{a, c, *}$ \\ ${ }^{a}$ Department of Chemistry and Biochemistry, University of Maryland, College Park, MD \\ 20742 \\ ${ }^{\mathrm{b}}$ Chemistry Division, Naval Research Laboratory, Washington, DC, 20375 \\ ${ }^{\mathrm{c} C h e m i c a l ~ P h y s i c s ~ P r o g r a m, ~ U n i v e r s i t y ~ o f ~ M a r y l a n d, ~ C o l l e g e ~ P a r k, ~ M D ~} 20742$ \\ rawalker@umd.edu

\section{Supporting Information}

The following supporting information section includes figures regarding data that are referenced in the article. Appropriate references are included.

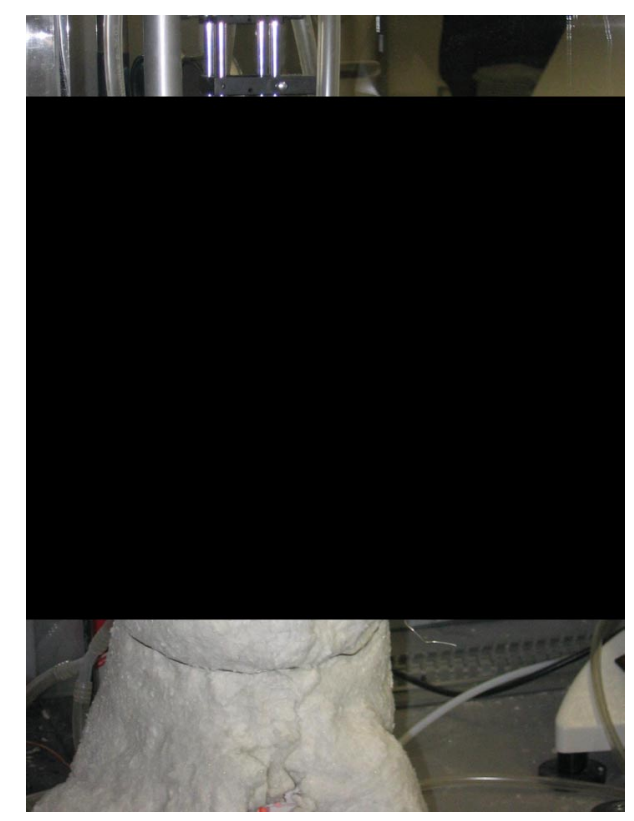

Figure SI1. A picture of the exterior of the experimental rig. The rig itself is contained inside a tube furnace (Thermcraft). A blue line is drawn to show the path of the $488 \mathrm{~nm}$ excitation. Signal collection occurs as $180^{\circ}$ reflectance of the incident beam. 


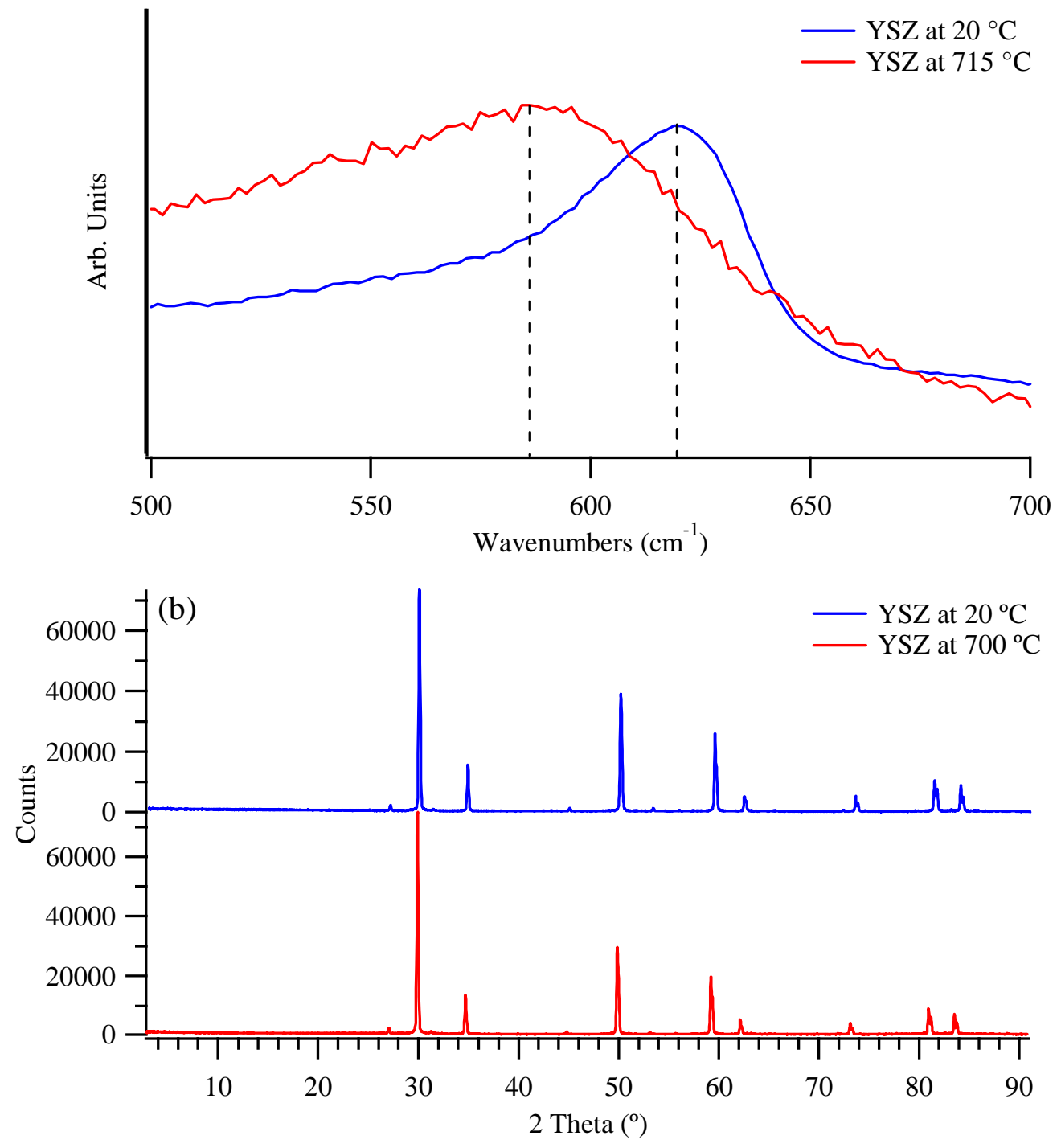

Figure SI2. (a) Raman spectra of the prominent $F_{2 g}$ peak of cubic $Y S Z$ at $20^{\circ} \mathrm{C}$ and $715^{\circ} \mathrm{C}$. (b) XRD patterns of the cubic YSZ lattice at $20^{\circ} \mathrm{C}$ and $715^{\circ} \mathrm{C}$. 


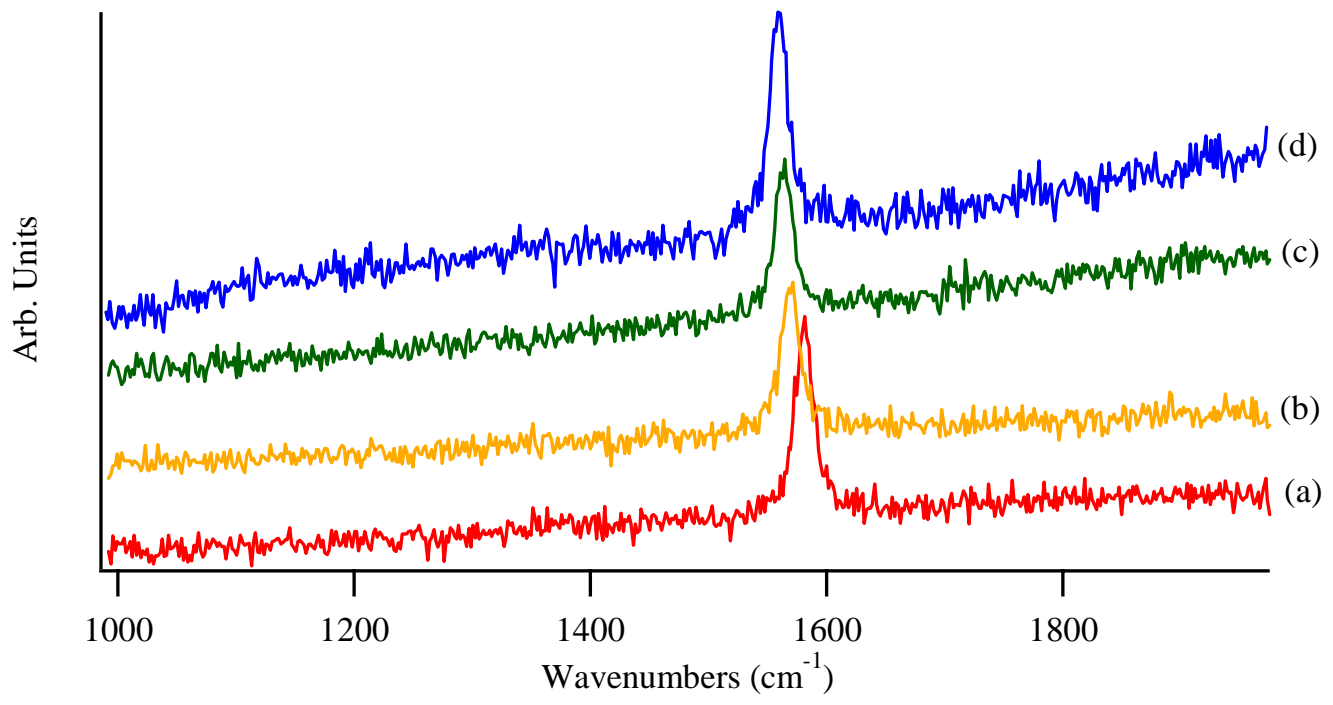

Figure SI3. Raman spectra of highly ordered pyrolytic graphite (HOPG) collected at (a) $20{ }^{\circ} \mathrm{C}$, (b) $570{ }^{\circ} \mathrm{C}$, (c) $640{ }^{\circ} \mathrm{C}$, and (d) $715{ }^{\circ} \mathrm{C}$ which show that the band shifts from 1581 to $1561 \mathrm{~cm}^{-1}$ within the experimental temperature range in a non-linear manner consistent with previous studies. ${ }^{1}$ 


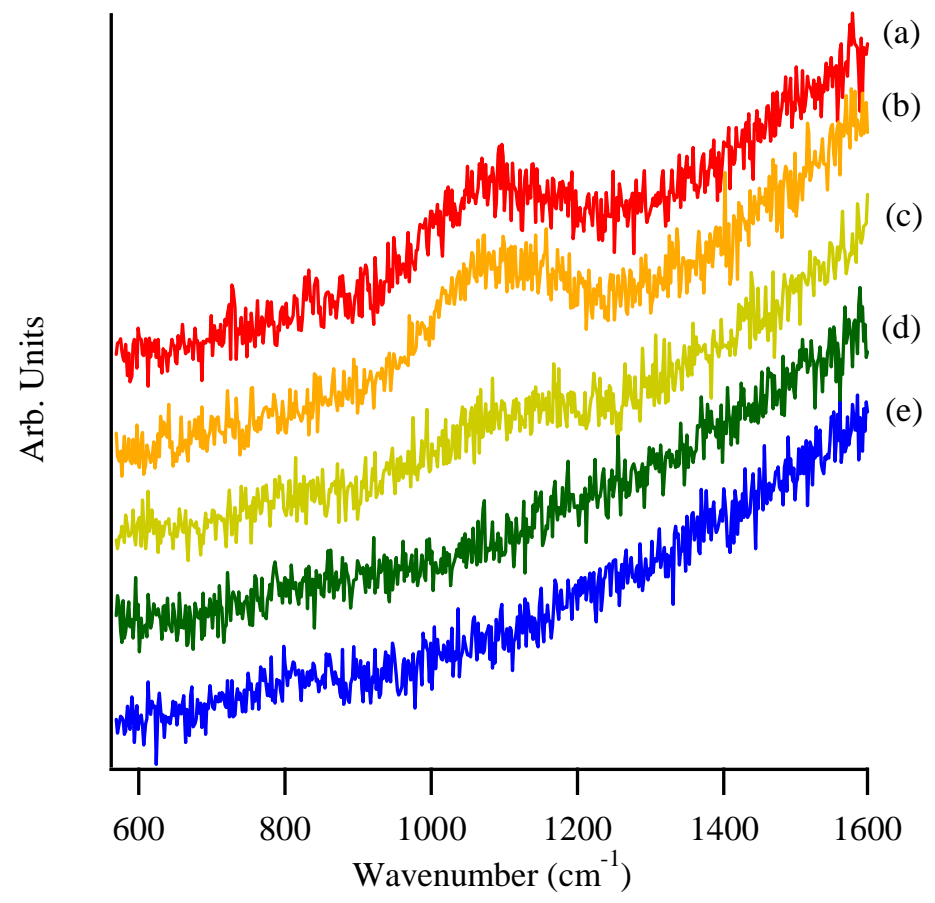

Figure SI4. Raman spectra showing the reduction rate of $\mathrm{NiO}$ in a wet $\mathrm{CH}_{4}\left(4 \% \mathrm{H}_{2} \mathrm{O}\right.$, $8 \% \mathrm{CH}_{4}$ in Ar) flow. The presented spectra where aquired (a) 0, (b) 3, (c) 4, (d) 5, and (e) 6 minutes after the introduction of wet $\mathrm{CH}_{4}$. The reduction rates are slower than in $\mathrm{H}_{2}$ where Ni reduction is complete within two minutes of initial exposure.

(1) Tan, P. H.; Deng, Y. M.; Zhao, Q.; Cheng, W. C. Appl. Phys. Lett. 1999, 74, 1818. 